\title{
THE MASTERING PROCESS AND THE SYSTEMS MODEL OF CREATIVITY
}

\author{
PHILIP MCINTYRE AND BRYAN PATON
}

\section{INTRODUCTION}

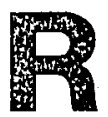

omanticism, in the form of the genius model of creativity, is a problematic position to sustain (Weisberg, 1993; Howe, 1999; Negus and Pickering, 2004; and Boden, 2004). While it is premised on a rejection of rationalism in favour of a predominantly metaphysical understanding (Sawyer, 2006: 15-18) romanticism has sustained itself remarkably well both as an intellectual tradition (Watson, 2005: 606-623) and in the public imagination. However, as Matthew Johnson claimed:

Romanticism is a state of mind, a set of cultural assumptions - one of the most successful discourses ever in terms of its infiltration into the cultural being and habits of thought of modern intellectual life, in that its assumptions have become so normal and natural as to be unspoken. (2007: 33)

Despite the heartfelt belief in romantic ideals held by many music practitioners, industry functionaries, music journalists and some academic critics (McIntyre, 2007: 85) the tenets of romanticism in popular music, and the related inspirationist understanding of creativity, are primarily untenable with little rationalist research evidence to support them. As Peter Wicke asserted:

[Music] as the individual expression of an outstanding artistic personality is de facto impossible. [Popular music has become] a collective means of expression, to which the individual musician can only contribute in a collective activity with others, with technicians, producers and, of course, with other musicians. (Wicke, 1990: 15-16)

If music making in the recording studio, as elsewhere, is indeed a collective process, it has been suggested that isolating authorship within music may be no more difficult than it has been in the case of film (Straw, 1999: 200). One of the 


\title{
Mclntyre and Paton
}

tactics to overcome the focus on singular authors in the field of popular music is to see the work that comes out of the recording process as "an interplay of skills and practices for which we credit a series of different people" (Straw, 1999: 200). Despite the unwillingness and inconvenience of seeing the function of personnel other than 'the artist' as central to this essentially collaborative process, either culturally or economically (Foucault, 1977; Bently, 1994), there is by virtue of seeing studio practice in action, little choice but to recognize that works produced in this creative exercise come about through collaboration. This article explores an important part of that process by focusing on mastering within a particular model of creativity and interaction.

\section{THE SYSTEMS MODEL OF CREATIVITY}

It is through the systems model of creativity that a reproduction and representation of the collaborative world of record making may be most readily seen. The model has been outlined by Mihaly Csikszentmihalyi. He argues that:

\begin{abstract}
For creativity to occur, a set of rules and practices must be transmitted from the domain to the individual. The individual must then produce a novel variation in the content of the domain. The variation then must be selected by the field for inclusion in the domain. (Csikszentmihalyi, 1999: 315)
\end{abstract}

Domains in this case are sets of inherited knowledges without which an individual cannot operate creatively - that frame the possibilities of action - and fields are social organisations that understand these knowledges. He has also argued that the system has a circular causality where "each of the three main systems - person, field and domain - affects the others and is affected by them in turn ... The starting point on this map is purely arbitrary" (Csikszentmihalyi, 1988: 329).

In making this observation Csikszentmihalyi points to the de-centred place the individual holds in the system. Robert Pope, in a generous critique of the systems model (2005: 67-70) argues that regardless of Csikszentmihalyi's "sensitivity to social networks and contexts" (ibid: 68 ) he still privileges the person. However, it should be noted that Csikszentmihalyi has asserted that "it is the community not the individual who makes creativity manifest" (1999: 333). This communal and collaborative aspect of creativity is a facet of the model that has been little discussed. While Csikszentmihalyi himself sees members of the field as gatekeepers, Keith Negus, realising the limitations of the term, gives preference to Bourdieu's concept of the cultural intermediary. Negus charac-terises the role of the cultural intermediary as "a series of interactions and mediations as people in particular occupations connect together and play an active part in the production, distribution and social consumption of popular music". (Negus, 1996: 67).

It should be noted then, that if the field is constituted by cultural intermediaries 
active in their mediations, then the field is also constituted by related individuals all of whom generate their own creative output within the system. This realisation adds a needed layer of complexity to the model not originally outlined by Csikszentmihalyi. It also underlines his apparent failure to "grasp the poststructural implications of a systems approach pushed to its logical and evolutionary limits" (Pope, 2005: 69). Fortunately the systems model, by placing a re-conceptualised emphasis on the individual, doesn't lead to the complete dissolution of the productive agent as extreme poststructuralist perspectives do (see Barthes, 1977; and Wolff, 1993) and leaves room for what Negus and Pickering call "a creative and yet conditioned sense of agency" (2004: 154). With the additional claim by Pope that "creative co-operation also has its technological dimensions" (2005: 69), Wicke appears supported in his claim that "music is created on foundations which, as the result of the technology of studio production, have a necessarily collective character" (1990: 16).

\section{THE RECORDING PROCESS}

The community of personnel involved in this collective and collaborative process includes, as Wicke points out (1990: 15-16), not only the musicians and producers but also the technicians who control and manipulate the studio technology. The designated audio engineer on a recording project is often seen as acting as a 'trusty lieutenant' to the record producer and is, increasingly, the producer themselves'. Whatever mode of collaboration they engage in, the engineer's primary role is to act as liaison between the producer and the technology, where their major creative function is to capture and manipulate sound in the way a cameraperson captures light (Emerick in Martin, 1983: $256-265$ ). Not only do they ensure the audio is handled well by the technology but they must also interpret the varieties of language used in the studio. This critical occupation can be further broken down into the subcategories of recording engineer or mix engineer, both of whom have differing roles according to the stages of the recording process being engaged with.

The process a song goes through to come to its realisation as a material object usually includes the standard conceptual, preproduction, production, postproduction and presentation phases. Once an idea is conceived of and bought into a material form there is then a degree of in-depth planning in organisational, equipment and budgetary terms required. These tasks usually fall under the purview of a producer during preproduction and involve identifying the specific resources needed, obtaining permits, clearances and insurance requirements, booking the talent, studios or necessary equipment, scheduling recording or programming times, organising transport if necessary and so on. The production stage includes the methods of actually accomplishing the objectives of the creative project. It is where the actuality of recording all the material for the creative object occurs and usually includes tracking and overdubbing with the principal players including the musicians, the producer and the audio engineer. The postproduction stage is the phase where the recording begins to come 
together as a complete entity. Postproduction is most often where mixing, editing and mastering, the subject of this paper, occurs. Mixing is the blending of various sounds into a cohesive combination that satisfies musical, sonic, technical, economic and personal criteria and is usually carried out by a mix engineer and overseen by a producer. While not as critical as mixing, editing is the practice whereby unwanted material is deleted, mistakes are fixed and song structures are rearranged. Mastering is the final stage of pre-production, and will be dealt with in more detail shortly. The presentation stage for the project includes making multiple copies of the production. It is after this point that the production of the song will meet its first external audience through distribution and promotion.

While it has been traditional to include songwriting in the conceptual and preproduction phases of recording one could also argue, as Fitzgerald has (1996: 20-21), that a song only comes into existence at the point of arrangement. As songwriter John Lennon has also contended, and has been argued elsewhere (McIntyre, 2006: 211; Hennion, 1983: 187-188), often a song may not be completed until it passes through one of the latter phases of the production process. Additionally, if reception is arguably anywhere near being the point of meaning-making and thus creativity, and if Csikszentmihalyi is at least partially correct in asserting that creativity comes about as the result of an interaction between audience and producer (1999: 313) then one could also argue that the role of the mastering engineer, as final manipulator of the sonic properties of the recording and thus a significant audience arbiter, is critical to a song's reception. So what is a mastering engineer? What do they do and what is the domain of knowledge they need to engage with in order to fulfill this significant role in the recording process?

\section{THE PLACE OF MASTERING IN THE SYSTEM OF RECORD PRODUCTION}

In order for a recording to sound reasonable to the audiences it engages with there are a number of elements that one could expect to be in place prior to mastering. Firstly, a sound source is required which is capable of being captured by the appropriate transducers or microphones with the captured audio then being fed through preamps that won't essentially alter the signal's basic tonal characteristics. Secondly, the audio needs, to be sent along a signal path without it being obstructed or distorted in some manner through to a recording medium which is also capable of relatively precise reproduction. Thirdly, the mix needs to be balanced within the aesthetic requirements of the musical project. The recording project will then almost be ready to be pressed and manufactured. However, the critical step we are primarily concerned with here, one that can affect the musical and audio content of the work in quite significant ways, is that of mastering. In simple terms mastering is the stage of post-production where the overall final product is adjusted so that it is intelligible, in audio terms, across all playback systems and, in this case, may be compared to the colour grading process undertaken in film work. Mastering may also be seen less positively as 


\section{Mastering Process and Systems Model of Creativity}

an attempt to compensate for possible losses of audio information during the manufacturing process. In accomplishing these tasks the role of the mastering engineer is one that has become increasingly important to record production. One of the foremost mastering engineers in Australia, Don Bartley, states that:

The word mastering originated from the early days of shellac and vinyl records. Mastering describes the process of creating a production master to facilitate manufacture of the final mass produced product. In days of old it involved a 1:I transfer of the audio, which was engraved or cut as a modulated groove on to a master disk (lacquer). This master lacquer was used to produce a metal mother from which a multitude of stampers were produced. The stampers were fitted into a hot press. The press was heated with steam and the stampers were pressed into shellac in the early days and vinyl in recent times to reproduce the modulated groove that originated from the mastering process. It wasn't until the late 1960's and early 1970's that the transfer of audio started to be processed. Equalizers and compressors were used to obtain a more musical result which enhanced the detail of the recording making the end result louder and more exciting. Nowadays this processing has become more akin to audio post production with the use of a multitude of effects and mixing devices to make the music shine within this highly competitive industry. (http://www.donbartley.com/ Australia/index.htm, accessed 22 May 2006)

Bob Katz, a pre-eminent mastering engineer from the US, outlines the place mastering holds in record production by stating that technically the process is called premastering since mastering is actually part of manufacturing. For Katz premastering includes "the artistic and technical tasks of sequencing (putting the album in song order) dynamics processing, leveling, equalization, noise reduction, even some mixing ... naturally the output medium of premastering is called the premaster but we usually label it master" (Katz, 2002: 18). Don Bartley concurs stating that 'mastering' is:

[An] American word and it was basically directed towards people who are just there to transfer signal from one format to the other, carefully, but not necessarily doing any manipulation. So it really came into being when they started cutting discs and doing cassette transfers. Those people were given the title of mastering engineer. But now what I guess you could call mastering engineers are the guys over at the $C D$ factory who actually do the blast master from a pneumatic or whatever. They could theoretically now be the mastering engineer. What we're doing now is not really mastering any more. It's definitely post-production, because we're doing massive amounts of manipulation of the sound. (i/v with the author, September 1997)

As Jeff Murphy asserts, using the commonly accepted designation, "mastering is 


\section{Mclntyre and Paton}

the final creative stage in the production of your recording and can be the difference between sounding like a professionally released disc and an amateurish-sounding, homespun effort" (http://www.geargenie.com/articles/ jeff_murphy_0516022.html, accessed 16 October 2002). Bob Katz concurs:

$[\mathrm{M}]$ astering is the last creative step in the audio production process, the bridge between mixing and replication - your last chance to enhance sound or repair problems in an acoustically-designed room - an audio microscope. Mastering engineers lend an objective, experienced ear to your work; we are familiar with what can go wrong technically and esthetically [sic]. (Katz, 2002: 11)

\section{THE DOMAIN OF MASTERING}

In a technical sense mastering, once stereo mixes are input into a digital audio workstation, typically consists of several related activities which may occur at varying times in the process, dependent on the mastering engineer's modus operandi. These now include track assembly, editing, equalisation, a variety of dynamics processing, level matching and track coding.

In terms of assembly the construction of a sequence of material during record production remains highly important. While John Berger argues that the "meaning of an image is changed according to what comes immediately before or after it" (1973: 29) it can be claimed that this Kuleshov effect is also true of song order. The list of songs to be compiled into a comprehensive whole will attempt to create an emotional journey for the listener and, as Katz argues, it is "possible to turn a good album into a great album just by choosing the right song order" (2002: 87). The task of deciding which songs work with each other is usually undertaken by the producer and/or musicians prior to mastering but many times the draft sequence may be changed or adapted once it is actually heard in situ. As Bob Katz asserts, "a good mastering engineer bridges the nebulous division between artist, producer and engineer - having heard thousands of albums and being au courant, he may provide useful guidance during this process" (2002: 87). Spacing between tracks or working out the spread times is also imperative to this process as well but this activity may more readily occur in the final stages of mastering when PQ or track coding is undertaken ${ }^{2}$.

Editing may occur early in the process. At this point the mastering engineer 'cleans up' the tracks, taking out any unwanted material, edits the extraneous material from each tune and may also, through the ease afforded by software such as Protools, restructure the songs themselves in collaboration or consultation with the producer and musicians. It is often at this point that the mastering engineer moves into the important phase of equalisation.

Equalisation for a mastering engineer is a process whereby the frequency pattern of the mix is adjusted to give the work an overall tonal balance suitable for a variety of playback mechanisms. It includes the use of spectrum analysers, 
various bandwidth filtering apparatus such as high-pass and low-pass filters and the application of parametric equalisers designed to manipulate the gain of particular parts of the frequency spectrum in conjunction with wide or narrow ' $Q$ ' settings ${ }^{3}$. It is a critical part of the mastering process as the boosting or cutting of certain parts of the frequency spectrum may enhance or degrade the experience of the piece of music as each area of the frequency spectrum may be associated with particular communicative and cultural functions. For example, as Craig Anderton (1978) claims, if lower bass (about $10 \mathrm{~Hz}$ to $80 \mathrm{~Hz}$ ) is missing from a recording there will be a perceived loss of depth and richness. Upper bass (about $80 \mathrm{~Hz}$ to $200 \mathrm{~Hz}$ ) gives a sense of power. In a musical sense it is this range that may entice people to dance as it is here that a rhythm section's energy is mainly located. Lower midrange (about $200 \mathrm{~Hz}$ to $500 \mathrm{~Hz}$ ) is where most accompaniment in music falls. Middle midrange (about $500 \mathrm{~Hz}$ to 2,500 ) is the home of the voice, the pitch of babies crying, the sounds of alarm, voices carrying all forms of messages. Without this frequency range being well represented in the mix a sense of the music being shallow and empty may occur for the listener. Anderton also asserts that not many recognisable notes live in the upper midrange area (about $2,500 \mathrm{~Hz}$ to $5 \mathrm{kHz}$ ) but it contains many harmonics and overtones giving a sense of 'presence' to the music. However, if there is too much of this frequency range present it will sound bright but only for a time. Not only is there a differential involved in terms of a listener's subjective appraisal of the absence of this frequency range but there is also a biologically related psychoacoustic phenomenon involved that predisposes listeners to fatigue quickly. They might not consciously know why but they will grow weary of the piece of music if there is too much information in this part of the audio range. As Anderton goes on to indicate, lower treble (about $5 \mathrm{kHz}$ to $10 \mathrm{kHz}$ ) consists mainly of hiss and is thought to be the limit of most people's hearing range with upper treble (about $10 \mathrm{kHz}$ to $20 \mathrm{kHz}$ ) being the realm of extremely subtle and delicate frequencies. If the listener has the ears to hear it this range gives a sense of 'liveness' to the work. As Craig Anderton has asserted:

[I]t is extremely difficult to reproduce adequately on any speaker system and, coupled with lower bass it is what makes a live audio experience different to a recorded one. If the systems you use can reproduce it, it's just like being there! (Anderton, 1978: 12)

With these ideas in mind it can be readily seen that a mastering engineer must be able to grasp that there are psychoacoustic aspects of what it is they manipulating in the stereo mixes. In this regard the perception of sound is a complex and dynamic process characterised by the interaction between the nature of the sound source, the acoustic properties of the sounds themselves, the listener's environment, and the physiological and psychological condition of the listener. Although this process is critical to the work, the mastering engineer's ability to explicate this as an acoustician is not a primary prerequisite in carrying out their functions. However, in working with producers and musicians, like the recording and mix engineers whose work they manipulate, mastering engineers must also be able to convert their understanding of the frequency spectrum, and the larger audio world they work in for that matter, into the studio language used by a 
variety of creative individuals involved in the collaboration. The engineer must be able to translate, for example, the idea that something is too 'nasal' into a process of boosting or cutting frequencies around $1 \mathrm{kHz}$. Similarly a knowledge of which frequency range relates to a 'warm', 'sweet', 'harsh', 'dull', 'boxy' or 'muddy' sound is critical to a mastering engineer's work environment. Don Bartley asserts that 'it's just ensuring that everything's there that they want to be there. So it does vary a lot. You don't go in and EQ everything. Sometimes you don't have to do anything' (i/v with the author, September 1997).

Once the complexities of equalisation have been dealt with the mastering engineer will engage in some form of amplitude or dynamics signal processing. While multi-band compressors and noise gates are commonly used, dynamics manipulation may also entail using expansion and limiting as well as, at times, processors known as de-essers which are themselves fast-acting compressors that act on "high frequencies by attenuating them" (Alten, 2002: 169). As Bacon explains, "compressors detect the level of the input signal and then reduce or boost it according to a preset rate" (1981: 200) which may have the perceptual effect of adding extra 'bite' or 'punch' to a track.

An expander works in a reverse fashion, by opening out or increasing the dynamics of a chosen track, and can be particularly useful for cleaning up slightly noisy sounds - by pushing down the noise floor - or for increasing, for example the ring of cymbal. Limiters simply prevent signals from rising in level beyond a chosen threshold point. (Bacon, 1981: 200-201)

By setting a limiter at a threshold of a $\mathrm{dB}$ or two below the limit of the point at which a program reaches overload or distortion, higher levels can be realised which may also add to the apparent loudness of a track which, in turn, may prove beneficial to the reception of the recording. To explore this a little more fully it can be seen that the intensity or loudness of sound signals is one of the primary determinants in the perception of not only sound source localisation and movement but also of more complex auditory phenomena such as speech and music perception. While a human's dynamic range of hearing is quite large (at least $120 \mathrm{~dB}$ ) and relatively independent of sound type, the ability to hear the smallest changes in the intensity of a sound signal is dependent on the properties of the sound type (Moore, 2003). It can be argued that the basis for differing discrimination abilities may be related to the capacity of the listener to detect changes in the spectral shape of sounds. When the intensity of a complex sound is increased there is a greater change in its spectrum due to the differential effects of intensity change on the various components of the sound (Green, 1993). This increase in apparent loudness, and the attendant effect described above, is often what is sought from a mastering engineer through their use of dynamics processors. This not only increases the level of excitement for the listener but, in a related way, also gives the recording a comparative advantage in terms of airplay. Most often, as Jeff Murphy suggests, the "use of compression is an art form unto itself and there are no hard and fast rules to follow. It can be a very slippery slope; not enough and the $\mathrm{CD}$ will lack volume and punch, too much and 


\section{Mastering Process and Systems Model of Creativity}

the disc will seem undynamic and lifeless" (http://www.geargenie.com/articles/ jeff_murphy-0516022.html, accessed 16 October 2002).

Manipulating the program material via a variety of processors in this way can result in a complex set of interactions occurring where the mastering engineer effectively produces what one could properly call a pseudo-mix. In order to accomplish this task, as both Katz (2002) and Murphy (2006) assert, monitoring is absolutely critical. Despite the proliferation of home studios a critical listening environment is still crucial to a reasonable or appropriate final product in order to be able to make judgments unhindered by sonic factors extraneous to the recording itself. As Anderton asserts, "very few houses were built with the idea that they would become studios one day" (1977: 31). But like most aspects of working with audio there is a great deal of compromise between a set of multiple complex sonic factors as there is, unfortunately, no perfect flat listening situation. Nonetheless, rooms used for monitoring, either dedicated studios designed for the purpose or conveniently located bedrooms, need to 'translate', that is, audio mastered in them should sound approximately similar in a variety of listening environments, including acoustically variable listening situations and playback apparatus. The other major factor governing accurate listening is a set of quality control room monitors or speakers. These may have a flat frequency response, in conjunction with the amplifiers and crossovers that are associated with them, or have their properties very well known to the mastering engineer so that they can make essential judgments using them. Both of these factors are critical as the speakers and the room may 'colour' sound and thus change the perception of the audio. They are both critical links to the audio on the recording medium and without them the mastering engineer will be listening blind.

\section{WORKING WITH THE DOMAIN AND FIELD: THE CASE OF DON BARTLEY}

Despite the proliferation of home studios and the availability of software programs such as Wavelab it can be seen that it is a mastering engineer's skill in using this equipment that is essential to the process, not access to the technology per se. Not only must they be able to operate the technology so this technical process becomes transparent but they must also know, most often at the level of tacit knowledge (Schon, 1983), what a mastered recording is capable of in musical and emotional terms (llie and Thompson, 2006: 319). The acquisition of this information is most often the result of an inculcation into the domain knowledge of mastering and an ability to read the field which allows engineers to 'feel' (see Schon, 1983: 55 and Johnson in Bourdieu, 1993: 5) their way to the most appropriate mastering output at the time they are working. So where does this knowledge come from? Weisberg argues that a deep immersion in the skills and knowledges of a domain is necessary for an individual to become effective in their field. He asserts that "deep immersion provides extensive opportunities for practicing any skills, such as playing the piano, required to create within the domain, which makes them automatic. Automaticity of skills may be necessary 
for the production of novelty" (1999: 247). This deep immersion in the domain of mastering can be seen in the case of Don Bartley and his career path.

Don Bartley has no formal musical qualifications; however his informal education began early.

Don grew up fascinated with sound. His father was trained as a radio technician and, as a child, Don watched and listened to him while he built and repaired valve radios. In the evenings they listened to the radio, and that's when Don discovered that sound can create images and he learnt the true meaning of "HI FI". Early in high school, Don was given a mono tape recorder, and he learnt to record, mix and edit. Soon Don moved on to a stereo tape recorder, home built amps, mixer and [a] pirate radio station. This is when The Beatles arrived and changed his life. (http://www. donbartley.com/Australia/index.htm, accessed 22 May 2006)

When Bartley left school he took on a job as an electronic technician in training and worked in the draftsmen's area of the electronics section of the Sydney Water Board. At the same time he undertook what was the equivalent of a TAFE course, known in those days as a Tech course. It was a course in Electronics and Communications and was the closest he could get to a course that would suit him. Along with this he did the Water Board's basic training which was equivalent to the former PMG basic training. While this electronics training informed his later work Don remembered that "when I started there were no courses in recording; courses in the music industry didn't exist. Anything you learnt was on the job" (i/v with the author, September 1997). Nonetheless, this combination of formal and informal approaches suited him well:

It was good because it gave me a good technical training at that particular time ... I ended up getting a job in electronics in the Water Board and they had a little bit of audio equipment which was used for sound level measurements for pumping stations and also a bit of two-way radio stuff and closed circuit TV. That was interesting and I learned a lot of basic stuff. (i/v with the author, September 1997)

After five years work at the Water Board a position came up at the Australian Record Company (now known as CBS) in 1971, for a technician/mastering engineer. It was here that his first serious encounter with the field of music, those who can affect the creative decision-making of record production, occurred. He was employed to be involved in new projects, developing and installing new equipment for CBS at their Artarmon plant.

I took that job and I saw this equipment up there that was used for cutting records and doing tape transfers and I just said 'nuh, I want to do this'. I mean, I like to do some technical things but I thought I really want to operate this equipment and work with audio. So they gave me a go at it and I went from there. I just started cutting records. My first job was actually putting together a compilation for 
Van Morrison. It was simply compiling from quarter inch to quarter inch and then after I'd compiled it I'd then transfer it onto lacquer for a record pressing. ( $\mathrm{i} / \mathrm{v}$ with the author, September 1997)

Bartley took on this work and during this period can be credited more than anyone else in Australia for developing the initial creative expertise in this area. Largely as a result of his own efforts, Bartley saw the transition of the occupation from, in Katz's terms, mastering to pre-mastering:
I was working on a lot of overseas product being released here and I'd be getting the overseas pressings and I'd be putting them on and comparing them to master tapes that they were sending over and they didn't compare! The pressings sounded different and better than the quarter inch master tapes that we were getting, so we started looking into that, and we found that they'd been spending a lot of time in America mastering the albums whereas we would just get the master tape and just transfer it straight across. It would probably take an hour or something - an hour and a half. They were actually spending, at that time, a day to master a record which we found quite fascinating. But nobody told us about this so we had to start questioning as to how to do it ourselves. I guess that's how [the change] happened. Porticularly in the case of local product because, once again, we'd been producing records for local bands in the seventies and we would compare them to overseas product, on vinyl this is, and ask 'why does the overseas product sound louder and more punchier than the local?' So it got to the point where clients, producers, etc, started coming in on the cut and we were spending half a day or a whole day just cutting an album. (i/v with the author, September 1997)

After working in this collaborative way with various members of the field, Bartley then shifted his employment to RCA Records where he was asked by his employers to head up "their new facility in 1975 after RCA's huge success with ABBA" (http://www.donbartley.com/Australia/index.htm, accessed 22 May 2006). The transitional aspect of mastering began to move along quite quickly at this point:

This really started to take off when I joined RCA because they'd just installed a brand new Neumann system which had a mastering console with compressors and equalisers and little toys, and producers started coming in and that's when I started to get a name I think, working with Charles Fisher and Peter Walker. They'd come in and we'd spend all day on one job and the next day l'd get into trouble because I'd spent all day just producing one album and they'd start yelling at me, you know. And I'd say 'this is what it's all about. This is what they do!' and they'd say 'we've got a production to run!' which is fair enough. They needed eight to sixteen lacquers a day to keep the factory going and I sort of said 'maybe you should 
get another mastering room,' and they said, 'oh no you can't do that!' Eventually I came over to 301 . (i/v with the author, September 1997)

In 1980, Bartley moved to EMI Record's Studios 301 where he also saw the transition of the music industry from an analogue based world into the digital age "and watched with sadness the demise of vinyl" (http://www.donbartley.com/ Australia/index.htm, accessed 22 May 2006).

EMI had several cutting rooms and they didn't have that pressure on them to produce, say, eight lacquers a day per person and I started working with clients. We didn't have that pressure of production because they had another room for production cuts. That's where I really got into working for clients for time really, instead of just doing production cuts. (i/v with the author, September 1997)

With the changes that were occurring in both the domain and field of the music industry during this period Don took on freelance engineering in 1980 and started his own company. International Mastering Services P/L worked predominantly out of his favoured location at 301 Castlereagh Street in Sydney. While Studios 301 , the business, has been since relocated to other facilities in Alexandria, a mastering service labelled Benchmark Mastering, of which Bartley is a part, still operates in the rooms on Castlereagh Street.

At 301, Bartley primarily worked with a locally modified EMI Abbey Road analogue TG mastering console in Mastering Suite One. As well as Sonic Solutions HD Workstations and the use of programs such as Digidesign HD ProTools, the studios were fitted with a set of dynamic processors and audio equipment from manufacturers such as TC Electronics, Focusrite, Tubetech, Neumann, Neve and others (http://www.301.com.au/301 sydney/301_Mastering/ mastering_equipment.html, accessed 21 June 2006). They were also fitted with Prism and Apogee AD/DA and Genex AD/DA converters and a spectrum analyser. While the studios were set up to input from a wide variety of formats such as DAT, CD-R, half-inch or quarter-inch 2-Track, Exabyte, U-Matic, 16 bit or 24 bit SD2, AIFF or wav file formats, Bartley eventually mastered to $C D$ and DVD formats, and occasionally SACD. At times he also routed audio through an Ampex ATR or Studer A820 analogue 2-track half-inch tape machine as part of the signal path in order to add their particular audio qualities to the final product. Bartley argued that:

If you've got something that's been recorded on a digital system with a digital recorder through a digital console it does tend to come out sounding brittle and hard. A little 'unmusical' if you like. By virtue of the fact that you run it through one analogue stage - say an analogue desk and an analogue tape - half inch for instance - that basically adds a little bit of the analogue warmth that's lacking out of the digital. It's probably also adding a certain amount of distortion, which I agree probably isn't the right thing to do from a 


\section{Mastering Process and Systems Model of Creativity}

technical point of view but from a musical view point it is quite musical distortion and it does smooth things out a bit. It just takes away those square waves that you used to have on the digital master and as you probably know you can't put square waves onto analogue tape. They tend to smooth back a little bit and they distort and you add a little harmonic thing to them. But this is what everyone's used to and it's what everyone's been hearing all these years and it's quite 'musical'. (i/v with the author, September 1997)

The monitors used in Studios 301 typically include speakers from Duntech, Orpheus and Dynaudio as well the occasional JBL shelf-type speaker placed on the floor to simulate car speakers. These have been critical to his process but as Bartley explains there is a degree of experimentation in finding just the right combination of adjustments across all of the activities any mastering engineer must grasp:

I guess if you've got a good song and you haven't quite had the budget nor the time to get the mix happening on it or to get a good sonic response you can do a lot with it. So for example the vocal is lacking a bit - you can actually get in there and pull their vocal out a bit more so you can hear the words, the lyrics. Or the rhythm section might be suffering a bit because of this general problem in the mix, a lack of warmth or something in the bottom end, and so you do a bit of compression in the bottom end - you add a bit of compressed bass so that the rhythm and the bass and the snare and everything is easy to hear and they sort of lock together better so the whole thing is musically clearer. Stereo-wise you can expand the stereo spectrum if guitars have been panned you can bring them out and make them louder and generally make the thing sound a bit bigger. Definitely you can make a difference ... The trick of it is to listen to the final mixes and to manipulate them so they are basically easy to listen to, [and] so you don't have to adjust your system. You can just put them on good and loud and everything's clear, there's plenty of top-end and bottom-end and good stereo spectrum happening. (i/v with the author, September 1997)

In the process of developing the skills to accomplish these things Bartley "built up a huge international client base" (http://www.donbartley.com/Australia/ index.htm, accessed 22 May 2006) accumulating over a lengthy period a significant number of accolades and awards for his work ${ }^{5}$. Apart from his copious and significant credits Bartley was also asked by EMI in 1982 to master an audiophile version of the Beatle's Sgt Pepper's Lonely Hearts Club Band (1967) album. Bartley has stated that:

[This was] a special time for me as I am also a Beatle 'nut'. The whole project was handled very well by EMI. I was given all the time that I needed to get it right and I seem to remember spending about 3 days on it. As it was a 'half speed' transfer there were many test 
cuts done, two of which I still have and I have never played them since that time. I remember spending many hours setting up for the 'secret' track in the lock groove at the end and somehow, I managed to get it exactly the same as the original Abbey Road 'cut'. The tapes used were specially sent out from Abbey Road, they were not the originals but 1:1 direct copies of the originals. They were 30 ips, Dolby $A$ and $I$ remember feeling quite privileged and lucky the moment I started to play them. The amazing thing about this project was that I was allowed to $E Q$ at my leisure and I must say that was a challenge especially working at half speed. I do remember listening to the test cuts at the time and thinking how fantastic it sounded. Since then I have quite a few people comment on its quality, including Ed Kuepper, who said it's the best version he has ever heard. (http://www.donbartley.com/Australia/index.htm, accessed 22 May 2006)

Bartley has worked closely with the field of popular music, including a wide array of nationally and internationally significant artists while continuing to nurture local unsigned musicians. He is aware that the process of mastering, over the course of the last fifty years, has become just as critical to a recorded song's success, and thus the ability of songwriters and musicians to continue to work in their chosen area. Rachel Rose, songwriter from independent band Doradus, explains how their recording, which was recorded in a number of situations, was made to sound cohesive:

Mastering helped bring that together. It sounded like two different bands before we mastered it but that brought it in line a bit because Don Bartley did such a good job. (i/v with the author, August 1996)

\section{CONCLUSION}

This short account of Don Bartley's history in the Australian music industry illustrates, for the purposes of this paper, not only the collaborative nature of record production but also the results of domain acquisition and the interaction necessary with the field. This "'taking in' of rules, values and dispositions" necessary to understand the domain and operate within the field has been labeled 'habitus' by Pierre Bourdieu (in Schirato and Yell, 1996: 42). This is internalised and then spontaneously acted out by both an individual or a collective during practice. Bourdieu has stated that:

[The] habitus, a product of history, produces individual and collective practices - more history - in accordance with the schemes generated by history. It ensures that active presence of past experiences, which, deposited in each organism in the form of schemes of perception, thought and action, tend to guarantee the 'correctness' of practices and their constancy over time, more reliably than all formal rules and explicit norms. (Bourdieu, 1990: 54) 


\section{Mastering Process and Systems Model of Creativity}

As has been argued elsewhere "it is a person's habitus that inclines, or predisposes, them to act and react in particular ways in particular situations" (McIntyre, 2006: 205). It is this ability, set up by his habitus, that has enabled Bartley to engage in a cultural practice which "circumscribes a cultural producer's choices while at the same giving them the ability to make those choices" (ibid). In this way creative individuals work within frameworks that shape and govern their creativity with the possibility of action occurring within or being produced by these frameworks. According to Jason Toynbee (2000) these include techniques and codes of production which may present themselves "to each agent as a space for possibles, that is as an ensemble of probable constraints which are the condition and the counterpart of a set of possible uses" (Bourdieu, 1996: 235). It is the manipulation of these that constitute a major part of the activity of creative individuals.

In apprehending this complex set of interactions Bartley's case exemplifies the set of relationships which exist for a cultural producer working within a collaborative process, the access they need to the domain they work within, including an awareness of the technological possibilities, and the necessary connection to the field of cultural production they carry out their creative work with. His ongoing contribution to the creative activity of record production in Australia as a respected and valued mastering engineer is a useful example of the nodal point around which the musical, the socio-cultural, the economic, the technological and creative possibilities intersect, which themselves have structured, limited and enabled his specific cultural practice. As such he is not only an example of the "intersection where individuals, domains and fields interact" (Csikszentmihalyi, 1999: 314) and thus an exemplar of the systems model at work, but he has also been a valuable collaborative contributor to recordings that have been promoted as the product of more prominent individual musical figures. His case demonstrates that, to repeat Wicke's assertion:

[Music] as the individual expression of an outstanding artistic personality is de facto impossible. [Popular music has become] a collective means of expression, to which the individual musician can only contribute in a collective activity with others, with technicians, producers and, of course, with other musicians. (1990: 15-16)

\section{ENDNOTES}

1. The stereotypical example is that of Geoff Emerick in his relationship with George Martin during their time working together at EMl's Abbey Road Studios in St John's Wood, London (Southall et al, 1997). Emerick went on to become a producer in his own right working with artists such as Elvis Costello.

2. $\quad \mathrm{PQ}$ encoding "allows a $\mathrm{CD}$ player to locate the required tracks and index points on a disc by providing begin access, end access and index points 10 'mark' parts of a track" (http://www.disk-edits.com.au/cdstandards.htm, assessed 19 February 2008). 


\section{Mclntyre and Paton}

3. Q setting refers to the width of the frequency band to be operated on.

4. For wideband or bandpass-filtered noise the smallest detectable change follows Weber's law, that is, the smallest change that one can detect in a stimulus is proportional to the relative magnitude. For other sound types such as pure tones the proportionality of Weber's law does not follow; as sound intensity increases so does the ability to discriminate the smallest change in pure tones, at least for sound levels below $100 \mathrm{~dB}$ SPL.

5. These awards are listed on Don Bartley's website at http://www.donbartley.com/ Australia/index.htm.

\section{BIBLIOGRAPHY}

Alten, S (2002) Audio in Media (6th edition), Belmont (California): Wadsworth/Thomson Learning

Anderton, C (1978) Home Recording For Musicians, New York: Amsco Publishers

Bacon, T (ed) (1981) Rock Hardware: The Instruments, Equipment and Technology of Rock, Melbourne: New Burlington Books

Barthes, R (1977) Image-Music-Text, New York: Noonday Press

Bently, L (1994) 'Copyright and the Death of the Author in Literature and Law', The Modern Law Review Limited, v57

Berger, J (1973) Ways of Seeing, New York: Viking Press

Boden, M (2004) The Creative Mind: Myths and Mechanisms, London: Routledge

Bourdieu, P (1990) The Logic of Practice, Cambridge: Polity Press

(1993) Field of Cultural Production (ed Randall Johnson), New York: Columbia University Press

(1996) The Rules of Art: Genesis and Structure of the Literary Field (trans by Susan Emanuel), Cambridge: Polity Press

Csikszentmihalyi, M (1988) 'Society, Culture and Person: A Systems View of Creativity' in Sternberg, $\mathrm{R}$ (ed) The Nature of Creativity: Contemporary Psychological Perspectives, New York: Cambridge University Press

HarperCollins

(1997) Creativity: Flow and the Psychology of Discovery and Invention, New York:

(1999) 'Implications of a Systems Perspective for the Study of Creativity' in

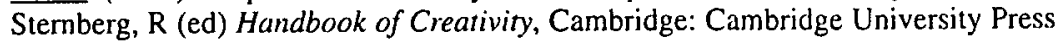

Fitzgerald, J (1996) Popular Songwriting 1963-1966: Stylistic Comparisons and Trends Within the U.S. Top Forty (Unpublished PhD Thesis: Southern Cross University) 


\section{Mastering Process and Systems Model of Creativity}

Foucault, M (1977) Language, Counter-Memory, Practice: Selected Essays and Interviews (ed Bouchard), Ithaca (New York): Cornell University Press

Green, D (1993) 'Auditory Intensity Discrimination' in Yost, W, Popper, A and Fay, R (eds) Human Psychophysics (volume 3), New York: Springer Verlag

Hayward, P (ed) (1990) Culture, Technology \& Creativity (in the Late Twentieth Century), London: John Libbey

Hennion, A (1990) 'The Production of Success: An Antimusicology of the Pop Song' in Frith, S and Goodwin, A (eds) On Record: Rock, Pop and the Written Word, New York: Pantheon Books

Howe, M (1999) Genius Explained, Cambridge: Cambridge University Press

Ilie, G and Thompson, W (2006) 'A Comparison of Acoustic Cues in Music and Speech for Three Dimensions of Affect', Music Perception, v23n4

Johnson, M (2007) Ideas of Landscape, Oxford: Blackwell Publishing

Katz, B (2002) Mastering Audio: The Art and the Science, Oxford: Focal Press

Martin, G (ed) Making Music: The Essential Guide to Writing, Performing and Recording, London: Pan

McIntyre, P (2001) 'The Domain of Songwriters: Towards Defining the Term 'Song", Perfect Beat: the Journal of Research into Contemporary Music and Popular Culture, v5n3

(2006) 'Paul McCartney and the Creation of 'Yesterday': The Systems Model in Operation', Popular Music, v25n2

(2007) 'Copyright and Creativity: Changing Paradigms and the Implications for Intellectual Property and the Music Industry', Media International Australia incorporating Cultural Policy, n123 May

Moore, B (2003) An Introduction to the Psychology of Hearing (5th edition), San Diego: Academic Press

Negus, K (1996) Popular Music in Theory: An Introduction, Cambridge: Polity Press

Negus, K and Pickering, M (2004) Creativity, Communication and Cultural Value, London: Sage

Pope, R (2005) Creativity: Theory, History, Practice, New York: Routledge

Sawyer, K (2006) Explaining Creativity: The Science of Human Innovation, Oxford: Oxford University Press

Schirato, T and Yell, S (1996) Communication and Cultural Literacy: An Introduction, St Leonards: Allen \& Unwin 


\section{McIntyre and Paton}

Schon, D (1983) The Reflective Practitioner: How Professionals Think in Action, New York: Basic Books

Straw, W (1999) 'Authorship' in Horner, B and Swiss, T (eds) Key Terms in Popular Music Culture, London: Blackwell

Toynbee, J (2000) Making Popular Music: Musicians, Creativity and Institutions, London, Arnold

Watson, P (2005) Ideas: A History from Fire to Freud, London: Weidenfeld \& Nicholson

Weisberg, R (1993) Creativity: Beyond the Myth of Genius, New York: W H Freeman \& Co

'Creativity and Knowledge: A Challenge to Theories' in Sternberg, R (ed)

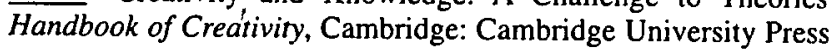

Wicke, P (1990) Rock Music: Culture, Aesthetics and Sociology, Cambridge (New York): Cambridge University Press

Wolff, J (1981) The Social Production of Art, London: MacMillan (1993) The Social Production of Art (2nd edition), London: MacMillan 